\title{
RECONCILING ASYMMETRIC INFORMATION AND DIVERGENT EXPECTATIONS THEORIES OF LITIGATION
}

\author{
Joel Waldfogel
}

Working Paper 6409 
NBER WORKING PAPER SERIES

\title{
RECONCILING ASYMMETRIC INFORMATION AND DIVERGENT EXPECTATIONS THEORIES OF LITIGATION
}

\author{
Joel Waldfogel \\ Working Paper 6409 \\ http://www.nber.org/papers/w6409
}

\author{
NATIONAL BUREAU OF ECONOMIC RESEARCH \\ 1050 Massachusetts Avenue \\ Cambridge, MA 02138 \\ February 1998
}

I am very grateful to Peter Siegelman for helpful discussions while developing the ideas in this paper. All errors are my own. Any opinions expressed are those of the author and not those of the National Bureau of Economic Research.

(C) 1998 by Joel Waldfogel. All rights reserved. Short sections of text, not to exceed two paragraphs, may be quoted without explicit permission provided that full credit, including $\odot$ notice, is given to the source. 
Reconciling Asymmetric Information

and Divergent Expectations Theories of Litigation

Joel Waldfogel

NBER Working Paper No. 6409

February 1998

\begin{abstract}
$\underline{\text { ABSTRACT }}$
Both asymmetric information (AI) and divergent expectations (DE) theories offer possible explanations of the litigation puzzle. Under DE, cases proceed to trial when, by chance, the plaintiff is more optimistic than the defendant. As the fraction of cases tried $(T)$ declines, this leads to a tendency toward 50 percent plaintiff win rates at trial $(P)$, regardless of the fraction of plaintiff winners in the filed population. Under AI, by contrast, informed parties proceed to trial only when they expect to win. Hence, as the fraction of cases tried declines, plaintiff win rates at trial tend toward either 0 or 1 . We present evidence that the relationship between $T$ and $P$ generated by the litigation process is consistent with DE and not AI. We also offer evidence of the presence of AI early in litigation in the form of one-sided plaintiff win rates in cases adjudicated prior to trial. We reconcile these two findings with evidence that pretrial adjudication and settlement culls both likely plaintiff winners and likely plaintiff losers from the filed pool, causing a tendency toward central rather than extreme plaintiff win rates at trial.
\end{abstract}

\author{
Joel Waldfogel \\ Public Policy and Management Department \\ The Wharton School \\ University of Pennsylvania \\ 3100 Steinberg-Dietrich Hall \\ Philadelphia, PA 19104-6372 \\ and NBER \\ waldfogj@wharton.upenn.edu
}


Two prominent theories offer possible explanations of the litigation puzzle, that parties fail to settle their cases and instead proceed to costly trials. These theories are the asymmetric information (AI) theory described in Bebchuk (1984) and the divergent expectations (DE) theory described in Priest and Klein (1984). ${ }^{1}$ In the DE theory, each party estimates case quality with error, and cases proceed to trial when, randomly, the plaintiff is sufficiently more optimistic than the defendant. Because this is likely to occur only for cases with true quality near the decision standard, cases far above and below the decision standard generally settle. The selection of cases under $\mathrm{DE}$ is thus two-sided, and it moves the plaintiff win rate at trial toward 50 percent regardless of the fraction of plaintiff winners among filed cases. In the AI theory one party knows the probability that the plaintiff will win at trial, while the other party knows only the distribution of plaintiff victory probabilities. When the defendant is better informed, the (uninformed) plaintiff makes a settlement offer, and it is accepted by informed defendants who face a relatively high expected liability at trial. The defendants proceeding to trial, on the other hand, are those who correctly expect to win. The selection of cases for trial is thus one-sided, and the plaintiff win rate at trial is systematically below the fraction of plaintiff winners in the filed pool. These theories share the prediction that tried cases are unrepresentative of filed cases. How the selection operates - whether one or two-sided - differs under the theories.

Most empirical work on the selection of cases for trial has been in the $\mathrm{DE}$ tradition, while the majority of theoretical work, much of it critical of the $\mathrm{DE}$ approach, has been in the AI tradition. ${ }^{2}$ Considerable evidence supports the main prediction of the DE model, Priest and Klein's 50 percent rule, that as the fraction of cases going to trial approaches zero, the plaintiff win rate at trial approaches 50 percent. Such evidence includes Priest and Klein's (1984) finding

\footnotetext{
${ }^{1}$ The model of Priest and Klein (1984) is in the tradition of Landes (1971) and Gould (1973).

${ }^{2}$ Empirical work in the DE tradition includes Priest (1986), Eisenberg (1990), Waldfogel (1995), Kessler, Meites, and Miller (1996), and Donohue and Siegelman (1995). A notable empirical exception which tests for AI in the criminal context is Froeb (1993). Theoretical work based on AI includes Grossman and Katz (1983), Hylton (1993), Shavell (1995), Spier (1992), and Nalebuff (1987). Wittman (1988) provides a theory that encompasses the Priest and Klein model as a special case.
} 
of 50 percent plaintiff win rates at trial in a variety of contexts, as well as Waldfogel's (1995) finding that, both across judges and across case types, as the trial rate approaches zero, the plaintiff win rate approaches 50 percent. However, some critics have noted that plaintiff win rates at trial deviate systematically from 50 percent. Notably, plaintiff win rates at trial in tort and civil rights cases are generally below 50 percent, which some observers regard as evidence favoring the AI theory over the $\mathrm{DE}$ theory.

Because the DE theory predicts 50 percent only as a limiting implication, plaintiff win rates deviating from 50 percent do not by themselves provide evidence against the $\mathrm{DE}$ theory. Both $\mathrm{DE}$ and $\mathrm{AI}$ are theories of the selection of cases for trial. Consequently, both theories predict both the fraction of cases adjudicated (which we term the adjudication rate, $T$ ), the plaintiff win rate among adjudicated cases $(P)$, and the relationship between $T$ and $P$. Because $\mathrm{DE}$ and $\mathrm{AI}$ provide contrasting descriptions of the selection process, they generate distinct, testable implications for the relationship between $T$ and $P$. This paper explores these distinct implications in section 1, and in section 2 we develop a test that distinguishes between $\mathrm{AI}$ and DE theories using variation in $T$ and $P$ across judges. In section 3 we present evidence that the relationship between $T$ and $P$ generated by the litigation process is consistent with $\mathrm{DE}$ and not AI. Although AI does not appear to explain the relationship between $T$ and $P$, section 4 presents evidence of the presence of AI early in litigation in the form of one-sided plaintiff win rates in cases adjudicated prior to trial. We then reconcile the evidence of AI early in litigation with the evidence that AI does not explain the selection of cases for trial with evidence, from adjudicated case outcomes, that pretrial adjudication and settlement culls both likely plaintiff winners and likely plaintiff losers from the filed pool, so that tried cases are not a one-sided selected sample of filed cases, as the AI theory predicts. 


\section{The Two Models and their Distinct Implications}

Both the $\mathrm{AI}$ and $\mathrm{DE}$ models generate predictions not only for the plaintiff win rate at trial $(P)$, but also for the trial rate $(T)$ and the relationship between the trial rate and plaintiff win rate. This section reviews the models and describes their implications for $P, T$, and the relationship between $T$ and $P$. The models share many predictons, for example for the effects of trial costs and prospective judgments on trial probabilities. The models can be used to generate distinct predictions, however, for the relationship between adjudication rates $(T)$ and plaintiff win rates among adjudicated cases $(P)$.

\section{The DE Model}

In the $\mathrm{DE}$ model parties disagree about the plaintiff's probability of winning a fixed judgment $J$ at trial. ${ }^{3}$ The parties form random but unbiased estimates of case quality. If $Y^{\prime}$ is true case quality, the plaintiff estimates the case quality to be $Y_{p}^{\prime}+\varepsilon_{p}$ while the defendant estimates the quality of the plaintiff's case to be $Y_{d}^{\prime}=Y^{\prime}+\varepsilon_{d}$, where $\varepsilon_{i}$ is a normal error $(i=p, d)$. The decision standard is $D$, which divides the population of filed cases (assumed to be distributed standard normal) into plaintiff winners and losers. At trial a case is decided for the plaintiff if its true quality exceeds the decision standard (if $Y^{\prime}>D$ ). Thus, plaintiff and defendant estimate the probability of plaintiff victory as: $P_{i}=\operatorname{Pr}\left(Y^{\prime}+\varepsilon_{i}>D\right)=\Phi\left(\left(Y^{\prime}+\varepsilon_{i}-D\right) / \sigma\right)$, where $\Phi$ is the standard normal cdf, $\sigma$ is the standard deviation of the parties' errors in estimating case quality, and $i$ indexes plaintiff $(p)$ or defendant $(d)$. Cases go to trial if the plaintiff is sufficiently overoptimistic relative to the defendant. If $C$ and $S$ are the parties' collective trial and settlement costs, trial occurs if $P_{p}-P_{d}>(C-S) / J$, which we term condition (1).

Three things affect the probability of trial through condition (1) in the DE model ${ }^{4}$ :

\footnotetext{
${ }^{3}$ See Priest and Klein (1984) for a full description of this model.

${ }^{4}$ The location of the decision standard $(D)$ also affects $T$ and $P$, although that effect is not relevant to the use of the model in this paper. See Priest and Klein (1984) or Waldfogel (1995) for discussions of the effect of the decision standard on both $T$ and $P$.
} 
1) the degree of uncertainty: as the parties' errors in estimating case quality $(\sigma)$ increase, the probability that the plaintiff's estimate of $P$ exceeds the defendant's estimate of $P$ by $(C-S) / J$ increases, and the probability of trial increases;

2) trial costs: the higher are trial costs relative to settlement costs, the lower is the probability that the plaintiff is sufficiently over-optimistic relative to the defendant, and the lower is $T$;

3) the prospective judgment upon victory at trial: the higher is $J$, the smaller is the margin by which the plaintiff must be over-optimistic. Hence, increases in $J$ make trial more likely.

In this model, settlement acts as a two-sided filter on the population of filed cases. If a case has true quality far above or below the decision standard, it is unlikely that the parties will disagree sharply about the plaintiff's prospects at trial. The cases most likely to go to trial are those with true quality near the decision standard, giving rise to the tendency toward 50 percent plaintiff victories at trial. As the degree of error in parties' case quality estimates declines, or if the relative gains from trade $(C-S) / J$ rise, the trial filter becomes finer. With more accurate estimates of case quality, higher trial costs, or smaller judgments, only cases closer to the decision standard go to trial, and the ensuing plaintiff win rates at trial converge to 50 percent.

The direction of convergence of $P$ toward 50 percent operates differently depending on whether the decision standard is above or below 0 (whether more or fewer than half of filed cases would yield plaintiff victory at trial). For example, with $D=1.5$, roughly 7 percent of filed cases would yield plaintiff victory at trial. If tried cases were drawn randomly from the population of filed cases, then roughly 7 percent of tried cases would yield plaintiff victory. When parties are poor at predicting case quality, trial costs are low, or the prospective judgment is large, the group of cases going to trial approaches a random sample from the filed case population. As the fraction of cases tried declines (for example because parties' ability to predict case quality improves), the plaintiff win rate at trial increases toward 50 percent. In $T-P$ space, if $D>0$ and 
$\sigma, C$, or $J$ vary, the relationship between $T$ and $P$ is negative with $\mathrm{P}<0.5$ With $\mathrm{D}<0$, the relationship between $T$ and $P$ is positive and $\mathrm{P}>0.5$.

\section{The Al Model}

In the AI model (see Bebchuk, 1984) a risk-neutral plaintiff sues a risk-neutral defendant for a fixed $J .^{5}$ Each party would bear costs $C_{i}$ at trial, where $i$ indexes plaintiff or defendant (settlement costs are assumed to be 0 ). The defendant knows that his likelihood of prevailing at trial is $p$, while the plaintiff knows only the distribution of $p$. The plaintiff makes a take-it-orleave-it settlement demand of the defendant.

The defendant accepts any settlement demand below his expected costs at trial. That is, the defendant accepts if $S \leq C_{d}+p J$, or if $p \geq \frac{S-C_{d}}{J}$. Thus, the defendant accepts an offer if the defendant's probability type $q$ (indicating the probability that the plaintiff will prevail against this defendant) equals or exceeds $q(S)$, where $q(S)=\frac{S-C_{d}}{J}$. Knowing this, the plaintiff chooses a settlement demand $S$ that balances the benefit of the higher settlement amount if received against the increased trial costs. In particular, the plaintiff chooses his settlement demand to maximize his expected position:

$$
A(S)=\{1-F[q(S)]\} S+F[q(S)]\left\{-C_{p}+J \frac{\int_{a}^{q(S)} x f(x) d x}{F[q(S)]}\right\}
$$

where $f$ and $F$ are the standard normal pdf and cdf, respectively and $a$ is the lower limit of the support for $p$. The optimal settlement demand $S^{*}$ divides defendants into those who expect (with high probability) to be found liable at trial, who accept the settlement offer and those who expect a low probability of being found liable at trial, who proceed to court. The first order

${ }^{5}$ See Grossman and Katz (1983) for an exposition of an AI model in the criminal context. 
condition (foc) and second order condition (soc) (along with other conditions outlined in Bebchuck, 1984) describe the optimal settlement demand and gives rise to the model's comparative statics. The foc may be written as $\frac{J}{C_{p}+C_{d}}=\frac{f\left(q^{*}\right)}{1-F\left(q^{*}\right)}$. The model's soc is that $f\left(q^{*}\right)+\frac{C_{p}+C_{d}}{J} f^{\prime}\left(q^{*}\right)>0$. The probability that the defendant loses at trial is unambiguously below the probability that the average defendant would lose at trial, if all filed cases were tried.

The AI model generates implications for not only the plaintiff win rate at trial but also the relationship between $T$ and $P$. As in the DE model, variation in either the size of the judgment $(J)$ or trial costs $(C)$ affect the trial rate. The model's soc implies that the right-hand side of the foc increases in $q$. Hence, increases in $J$ increase, and increases in trial costs decrease, the probability of trial. ${ }^{6}$ Variation in the trial rate has a different effect on the plaintiff win rate at trial in the AI model than in the DE model. Decreased trial rates induced by smaller $J$ (or larger $C$ or smaller $\sigma$ ) in the DE model cause the plaintiff win rate to converge to 50 percent. In the AI model with a better informed defendant, by contrast, decreased trial rates induced by increased $J$ (or decreased $C$ ) cause the plaintiff win rate at trial to approach zero. To see this, note that tried cases in the AI model with an informed defendant are those with expected plaintiff victory probabilities below some threshold $q^{*}$. Holding constant the distribution of $p$, increases in the fraction of cases tried (which correspond to an increase in $q^{*}$ ) also raise the ensuing plaintiff win rate at trial: $\int_{a}^{q^{*}} x f(x) d x .^{7}$ This prediction is analogous to the prediction derived and tested in Froeb (1993) in the criminal context.

\footnotetext{
${ }^{6}$ Increases in $J$, all else constant, make trials more likely. It is possible that increases in $J$ induce endogenous changes in trial costs. Empirical tests below will determine whether such possible endogenous changes in trial costs prevent variation in $J$ from affecting $T$.

${ }^{7}$ This comparative static does not hold for all factors inducing variation in the trial rate. Variation across groups of cases in the variance of $p$ motivate the opposite relationship. As this variance declines, the amout of information asymmetry declines, as does the trial rate. The plaintiff win rate at trial then converges to the mean of the $p$ distribution, rather than zero.
} 


\section{Comparing the Models}

Both DE and AI theories offer descriptions of the selection of filed cases for trial, and the samples tried under the two theories are quite different. In the AI theory with informed defendants and uninformed plaintiffs, for example, the plaintiff's take-it-or-leave-it settlement demand is accepted by relatively "guilty" defendants, leaving a disproportionately innocent group of defendants going to trial. The selection of cases for trial under AI is thus one-sided. Plaintiff win rates at trial are not only unrepresentative of the fraction of plaintiff winners among filed cases; with better informed defendants, plaintiff win rates at trial are systematically below the fraction of plaintiff winners among filed cases. In the DE theory both parties are equally (un)informed, and cases proceed to trial when (by chance) the plaintiff is sufficiently overoptimistic relative to the defendant. The farther that cases are either above or below the decision standard, the more likely it is that both parties will recognize the probable outcome, and the less likely is trial. Thus the selection of cases for trial under DE is two-sided.

\section{Do the Data on the Relationship between $T$ and $P$ Favor AI or DE?}

\section{Data and the Natural Experiment of Random Assignment of Cases to Judges}

The data for this study include over 65,000 federal civil cases filed in the Southern District of New York (SDNY) between 1979 and 1986 and terminated by the end of 1989 . Variables in the data include: whether the case is adjudicated or if not, (we infer) settled; whether the case is decided for the plaintiff if adjudicated; the procedural progress at termination, ${ }^{8}$ and the size of the money judgment for the plaintiff. These data are drawn from the AO data set. In addition the data set includes the judge to whom the case is assigned. These were obtained from the civil index in the SDNY clerk's office. They are linked with the AO data by docket number.

\footnotetext{
${ }^{8}$ Procedural progress indicates how far the case had proceded at termination. Possible values for this variable include: before issue joined (before the complaint is answered by the defendant); after motion, before issue joined; after issue joined, before motion; after issue joined, after judgment on motion; after pretrial conference (where discovery is scheduled); during court or jury trial; and after court or jury trial.
} 
Cases are randomly assigned to judges in SDNY. Consequently, over large numbers of cases, each judge has the same average caseload. Differences in average litigation outcomes across judges are therefore ultimately attributable to characteristics of the judges, rather than the cases or parties before them. If judges provide parties with different litigation environments, then random assignment allows simple measurement of the effects of these environmental differences. For example, as we explore below, if judges differ in the size of the judgments awarded in their courts, then we can test whether judgment size affects the tendency for parties to settle by checking whether judges with higher average judgments also have higher average adjudication rates.

\section{Distinguishing between the Theories}

Data on the relationship between the adjudication rate $(T)$ and the plaintiff win rate among adjudicated cases $(P)$ can distinguish between the two theories. Various researchers argue that tort and civil rights cases provide suitable contexts for testing the AI theory because they are characterized by uninformed plaintiffs suing informed defendants, as in the standard version of the AI theory. ${ }^{9}$ Below we initially focus on tort and civil rights cases, two categories in which the information structure corresponds to the assumptions of the basic AI model.

With better-informed defendants, the AI theory predicts that decreases in the trial rate induced by lower potential judgments will be accompanied by lower plaintiff win rates at trial. As the adjudication rate $(T)$ approaches zero, the plaintiff win rate $(P)$ also approaches zero. The $\mathrm{DE}$ theory generates a sharply different prediction: reductions in $T$ caused by smaller potential judgments cause $P$ to approach 50 percent. If one knows whether the decision standard is greater or less than 0 (whether more or fewer than half of filed cases would be plaintiff winners if all were tried), then the $\mathrm{DE}$ theory gives a more specific prediction. If fewer than half of filed cases

${ }^{9}$ Bebchuk (1984) introduces the model and invites the reader to view tort cases as an example with uninformed plaintiffs. Hylton (1993) cites tort, employment discrimination, and antitrust as case types amenable to the asymmetric information model he advances. 
are winners $(D>0)$, then DE predicts that $P=0.5$ when $T=0$ and that $P$ declines as $T$ increases. If $D<0$, then $\mathrm{DE}$ again predicts that $P=0.5$ when $T=0$ but as $T$ increases, $P$ increases. Given that plaintiff win rates in adjudicated tort (and civil rights) cases average far below 0.5 , it is likely that $D>0$ for these case types. ${ }^{10}$ Consequently, under DE we expect $P$ to decline from 0.5 as $T$ increases.

The first step in testing between the theories is to look for significant inter-judge variation in the theories' determinants of trial (such as judgment sizes and trial costs), adjudication rates, and the relationship between trial and its determinants. While we lack data on litigation costs, we do observe the size of monetary judgments, and we can compare these across judges to check whether judges before whom larger judgments are made also have higher adjudication rates (as is predicted by both $\mathrm{AI}$ and $\mathrm{DE}$ theories). Ideally we would like to have a measure of the judgment that a randomly winning plaintiff would receive before each judge. Instead we observe the judgments awarded in the relatively small (and selected) sample of adjudicated cases. Even ignoring any potential selection problem, it is difficult to obtain enough judgment observations per judge to allow meaningful comparisons within case types. In order to obtain a large number of judgment amounts per judge, we need to aggregate over all case types. We return to the possible selection problem below.

We observe money judgments for 6430 cases. The "amount received" variable reported in the AO data is top-coded at 9999 (for judgments above $\$ 9.999$ million). Six percent of the judgments in the sample are coded in this way. Although we cannot know the exact value of judgments of $\$ 10$ million or more, we can fit the observed judgments to a distribution, then draw from the distribution and compute the mean of judgments over $\$ 10$ million. We do this in the following way. First, because the distribution of judgments is very skewed, we fit a distribution to natural logs of judgments. We estimate a tobit model on log judgments, which gives estimates of the mean and standard deviation of the distribution of log judgments. We drew 200,000

\footnotetext{
${ }^{10}$ Waldfogel (1995) estimates the implied tort decision standard $(D)$ to be 0.510 . 
random observations from the estimated distribution. After exponentiating the simulated judgments, we then calculate the average judgment exceeding $\$ 9.999$ million to be $\$ 48.875$ million. In what follows we use the adjusted measure of judgments, in we recode 9999 to $\$ 48.9$ million. We also treat the small number of judgments for the defendants as negative, so that the average indicates average judgments in favor of plaintiffs. This recoding has a substantial effect on the average judgment but (because raw and adjusted judgments are highly correlated - 0.99 across judges) little effect on other results. The raw average judgment among the judges included in the study is $\$ 929,100$, while the adjusted average is $\$ 3,436,500$.

We use the overall average money judgment as our measure of the prospective judgment $(J)$ and the fraction of filed cases which are adjudicated as our measure of $T .{ }^{11}$ One can reject the two hypotheses of no judge effects on judgments and adjudication rates. As table 1 indicates there is substantial inter-judge variation in mean raw and adjusted judgment size. ${ }^{12}$ Adjudication rates also vary substantially by judge.

Figure 1 shows a positive relationship between the overall adjusted judgment size and both overall and tort and civil rights adjudication rates, consistent with both theories. Weighted least squares regressions (using the number of overall and tort and civil rights cases per judge as weights) confirm that the positive relationships are significant (in one-sided tests). See table 2 , column 2. We obtain a similar result regressing tort and civil rights $T$ on tort and civil rights judgments (see table 2, column 3). ${ }^{13}$

Given inter-judge variation in adjudication rates $(T)$ induced by inter-judge differences in $J$, it is possible to test between theories. For a first pass we examine the raw relationship

\footnotetext{
${ }^{11}$ The average tort and civil rights judgment $\left(J_{T C R}\right)$ is strongly and positively related to the average overall judgment $(J)$. See table 2 , column 4 . Because of the relatively small number of tort and civil rights cases per judge, $J_{T C R}$ is measured with error. Its use as a regression explanatory variable would result in a downward-biased coefficient, and it is better replaced by $J$.

${ }^{12}$ Across judges the mean and median judgment sizes are strongly positively correlated, indicating that inter-judge differences in judgment amounts are not driven by outliers.

13 The positive relationships persist, albeit less significantly, when we discard the potentially outlying observations with $T>35$ percent. 
between $T$ and $P$ for tort and civil rights cases, shown in figure 2. A regression of $P$ on $T$ confirms what is visible to the naked eye: there is a significant negative relationship between $T$ and $P$. See table 2, column 1. As $T$ approaches zero, furthermore, $P$ approaches 36 percent. In both theories $T$ is an endogenous variable determined by $J$ as well as other factors. Consequently, the relationship between $P$ and $T$ measured in the OLS regression may reflect variation in $T$ induced by factors other than $J$. Because we observe $J$, we can test between the theories cleanly by measuring the relationship between $P$ and the variation in $T$ induced by $J$. We accomplish this using instrumental variables, with $J$ as an instrument for $T$. The resulting weighted least squares IV regression is reported in table 2, column 5. This regression again shows that as $T$ approaches zero, $P$ approaches roughly 40 percent. Standard errors are higher in this regression, although the negative relationship is still significant at the 10 percent level. The negative relationship between $P$ and $T$ is consistent with the DE theory but inconsistent with the AI theory. We obtain very similar results using adjusted tort and civil rights judgments as instruments for $T$ (see table 2, column 6).

\section{Discussion}

The test in this section indicates that the settlement process (the selection of cases for adjudication) does not obey the basic implication of the AI theory. This result contrasts with Froeb's (1993) finding of a negative relationship between the probability of criminal trials and the probability of guilty verdicts, a finding consistent with AI. One reason why implications of AI theory are not borne out in data may be that actual civil litigation does not proceed in a way that corresponds to the conditions of the theory. The bargaining environment of the basic theory (see Bebchuk, 1984) includes a take-it-or-leave-it offer by the plaintiff which the defendant then either accepts or rejects. In actual civil litigation, long periods of time typically elapse between filing (and presumably the plaintiff's first settlement offer) and trial. It is difficult to believe that no additional bargaining occurs, and that the plaintiff receives no additional information from the 
defendant, save through the decision whether or not to accept the initial offer. For this reason, it may be mistaken to look to the relationship between $T$ and $P$ for evidence of asymmetric information in civil litigation. The criminal context may conform more closely with the setup of the model. For example, it seems more plausible that criminal prosecutors make take-it-or-leaveit offers.

\section{Early Adjudications: A Reasonable Test for AI}

Although neither trials nor adjudications generally appear, on their face, to provide circumstances consistent with the conditions of the theory, the litigation process does generate circumstances that may be useful for detecting the presence of asymmetric information. While most theories treat litigation as settlement bargaining in the shadow of a single-round of adjudication (a trial) if the parties fail to settle, real litigation is somewhat more complicated. Adjudication can occur even if the parties do not intend to proceed to trial. Indeed, the vast majority of adjudicated cases are adjudicated long before a trial would have occurred. ${ }^{14}$ Over half of adjudicated cases in the sample below are resolved on motions prior to the pretrial conference. These adjudications include summary judgments and other decisions that judges can make even with the limited information available to them on a case early in its progress through the litigation process.

The $\mathrm{AO}$ data indicate the "procedural progress" at termination, which allow us to determine how far a case has progressed. We aggregate the levels of procedural progress at termination into four rounds: 1) before the plaintiff's complaint is answered; 2) after the plaintiff's complaint is answered but before the pretrial conference where discovery is scheduled; 3) after the pretrial conference but before a trial begins; and 4) after a trial begins. Table 3 shows the distribution of cases by their procedural progress at termination, along with the average time elapsed between filing and termination, separately for tort and civil rights cases, as well as for

\footnotetext{
${ }^{14}$ See Eisenberg (1991).
} 
four other broad categories of federal civil litigation. Like the data above, these data include cases filed in SDNY between 1979 and 1986. Of the 10,673 filed tort cases in the sample, a quarter (2583) are terminated before the plaintiff's filed complaint is answered. Of these 2583 early terminations, roughly 20 percent (462) are adjudicated. Over a third (1770) of the 4598 civil rights cases in the sample are resolved before the complaint is answered. Over a third (593) of the 1770 early terminations are adjudicated. Cases in which adjudication occurs before the complaint is answered are much shorter than cases proceeding to trial, or even average cases. Tort and civil rights cases resolved before the complaint is answered last an average of 8.4 and 6.7 months, respectively, compared with 19.5 and 23.4 months for tried cases and 14.0 months for all tort and civil rights cases.

We can use the results of early adjudications as a test for the presence of asymmetric information among litigants. Suppose that shortly after filing the judge stands ready to adjudicate cases which (to the informed litigant and the judge) would have obvious outcomes at trial. Figure 3 represents this idea. Each case is summarized by the probabilty that the plaintiff would win at trial, $p$, and cases are distributed $f(p)$. All cases with $p<a$ would be adjudicated early in favor of defendants, while cases with $p>b$ would be adjudicated early for plaintiffs. An uninformed plaintiff knows the distribution $f(p)$ but does not know $p$ for her case. If the defendant is better informed (i.e. knows $p$ ), then if $p>b$ the defendant knows that the case would very likely be adjudicated for the plaintiff. Hence, a better informed defendant will accept plaintiff settlement offers in cases with $p>b$ and will reject settlement offers when $p<a$, allowing the likely plaintiff losers to proceed to adjudication. The testable implication of AI with a better informed defendant is a very low plaintiff win rate among cases adjudicated early.

If the informational asymmetry and bargaining structure are reversed - so that the plaintiff is better informed - then the implications change. The informed party again agrees to settle cases unfavorable to him, leaving only cases favorable to the informed party for adjudication. With an 
informed plaintiff and an uninformed defendant, the testable implication of $\mathrm{AI}$ is a high plaintiff win rate among cases adjudicated early.

Some evidence supports our characterization of early adjudication as a mechanism for culling outlying cases (obvious winners or losers) from the filed population, although we must admit at the outset that it is difficult to obtain an objective empirical measure of case obviousness. Mindful of this inherent difficulty, we nevertheless tried to characterize the process by looking for published opinions on Lexis in a random sample of 778 tort cases resolved at the four procedural rounds. One measure of legal "obviousness" is whether an adjudication generates a published opinion. We presume that judges write opinions in order to generate precedent. If a case raises no novel issues - which is related to whether the case has an obvious outcome - then the judge is less likely to produce an opinion. Our data show that opinions are quite rare in cases adjudicated in round one. Only 3.7 percent of these adjudications ( 6 of 161 cases examined) have corresponding opinions. Published opinions are increasingly likely for cases adjudicated at later stages: Published opinions are available for 13.1 percent (26 of 198 cases) of cases adjudicated at round two, 13.2 percent (27 of 204 cases) at round three, and 19.1 percent ( 41 of 215 cases) at round four. We view this pattern as evidence that earlier-stage adjudication culls obvious cases from the pool.

Previous researchers have argued that tort, employment discrimination, and antitrust cases have better informed defendants than plaintiffs. Our data on tort and civil rights (a major category of which is employment discrimination) cases correspond to this information structure. We also have data on four additional categories of federal litigation: prisoner petitions, labor cases, contracts, and intellectual property. ${ }^{15}$ It is difficult to obtain a priori information on the direction of informational asymmetry in litigation. One observable variable that may reflect plaintiff ignorance is the fraction of pro se plaintiffs in a case category. Siegelman and Waldfogel (1997) calculate this fraction for each of the six broad categories of litigation included

\footnotetext{
${ }^{15}$ See Siegelman and Waldfogel (1997) for information about these case categories.
} 
here. ${ }^{16}$ It is very high for prisoner cases (64.4 percent), high for civil rights cases (21.1 percent), intermediate for tort ( 5.9 percent) and labor cases ( 5.0 percent), and zero for both contracts and intellectual property (see table 3). Consequently, we expect plaintiffs in civil rights and, especially, prisoner cases to be ill-informed relative to their defendants; and we expect plaintiffs in contracts and intellectual property cases to be better informed relative to their defendants. Labor and tort plaintiffs should be somewhere in between.

A second variable that may reflect the direction of informational asymmetry across parties is the fraction of parties that are institutions (corporations or governments), as opposed to individuals. Table 3 reports the fractions of institutional plaintiffs and defendants in our case categories (again from Siegelman and Waldfogel, 1997). Three of six case types, tort, civil rights, and prisoner, are particularly unbalanced: They have almost exclusively individual plaintiffs suing largely institutional defendants. The other three categories are balanced: Institutions make up roughly three quarters of parties on both sides of those disputes. It seems reasonable to assume that individuals are less sophisticated litigants than institutions. ${ }^{17}$ If this is true, then we expect relatively greater plaintiff ignorance in prisoner, tort, and civil rights cases. The pattern of informational asymmetry implied by party identity is similar to the pattern implied by the fractions of pro se plaintiffs across case types.

\section{Settlement Under Asymmetric Information Gives Priest/Klein Results}

The selection of cases for trial is not properly characterized as one party's response to the other party's take-it-or-leave-it offer. Instead, the selection of cases for trial is a sequential process of settlements in the shadow of pretrial adjudication. ${ }^{18}$ Much adjudication - and much settlement - takes place long before a trial would occur. Our data allow us to determine the

\footnotetext{
${ }^{16}$ Calculations are based on case information on Lexis for random samples of 1533 cases from the underlying data set. See Siegelman and Waldfogel (1997) Appendix: Data and Methodological Issues for details.

17 Eisenberg and Farber (1995) make a related assumption about the difference between individual and institutional plaintiffs. They assume that individuals (who are potential plaintiffs) have a wider distribution of litigation costs. ${ }^{18}$ See Spier (1992) for a formal model of the dynamics of pretrial negotiation.
} 
juncture at which cases terminate. In addition to the cases (examined above) terminating in the first round of litigation (before the complaint is answered), we also observe cases terminated after the complaint is answered but before discovery is scheduled (which we term the "second round"); after discovery is scheduled but before trial begins (the "third round"); and after trial begins (the "fourth round").

Table 4 shows plaintiff win rates in case adjudicated in the first round for each of the six case types. A striking feature of these win rates is that they are extreme - either close to zero or close to one. Early plaintiff win rates in tort, prisoner, and civil rights cases are close to zero; and early win rates in the other three categories are close to one. These data are consistent with asymmetric information at the time of filing. In particular, these patterns would arise if defendants had better information than plaintiffs in tort, civil rights, and prisoner cases; and the opposite pattern of informational asymmetry held for the other three case types. ${ }^{19}$

In addition to the cases removed from the filed pool in the first round, another set of cases is removed in the second round. Assuming that second round adjudication operates in the same manner as first round adjudication (as a threat to adjudicate cases with $p$ outside of some set), plaintiff win rates in second round adjudication provide an additional test for AI. Plaintiff win rates should again be extreme (low if the defendant is better informed, high otherwise), but because the most obvious cases have already left the pool, the plaintiff win rates in the second round should be less extreme than in the first round. This prediction is borne out in the data. With the slight exception of prisoner cases, plaintiff win rates in second round adjudication are less extreme than first round plaintiff win rates (see table 4).

The third round of adjudication occurs after discovery is scheduled but before trial. The data do not indicate the quantity of discovery completed before termination, although the average

\footnotetext{
${ }^{19}$ These extreme plaintiff win rates are also inconsistent with the limiting implications of the Priest and Klein (1984) DE model. Under standard divergent expectations assumptions both parties estimate case quality in an unbiased but noisy fashion. Consequently, both obvious losers and obvious winners settle prior to adjudication. The data on early adjudications, by contrast, show that "obvious" cases proceed to early adjudication, suggesting informational asymmetry.
} 
durations of cases completed in this round is four months longer than the average for cases completed in round two. This suggests that some discovery occurred. Given the nature of discovery as an institution by which parties obtain information about their opponents' cases, it may be wrong to view the third round settlement as motivated simply by the threat of third round adjudication. Indeed, although settlements outnumber adjudications at all three pretrial rounds, settlements more distantly outnumber adjudications at round three..$^{20}$

One can compute very rough settlement hazard rates for each round as the number of cases settled in that round divided by the number of cases still active. This is converted to a monthly rate by dividing the hazard rate for the round by the average number of months in the round. Settlement hazard rates computed in this way peak for all case categories (except prisoner) in the third round, suggesting that discovery promotes settlement. The peak in the settlement hazard rate at this juncture suggests that the information transmitted across parties during discovery promotes settlement. Table 4 reports monthly settlement hazard rates for each round.

Parties in the selected sample of cases going to trial have completed discovery and therefore have more information about their opponents' cases than they had at filing. The amount of informational asymmetry should have been vastly reduced. In addition, the process of pretrial adjudication and settlement has removed the cases with obvious outcomes. Consequently, we expect plaintiff win rates among cases going to trial to be less extreme than at earlier rounds. This is borne out in the data. Plaintiff win rates at trial are less extreme - closer to 50 percent than at round three - for each case category (see table 4).

Figure 4 plots plaintiff win rates among adjudicated cases for each round and for each case type. The pattern in the figure is striking. Plaintiff win rates among adjudicated cases are declining by round for case types with high early win rates, and win rates rise by round for case types with low early win rates. Roughly speaking, the later the round in which adjudication

${ }^{20}$ See Cooter and Rubinfeld (1994) and Hay (1994) for discussions of the purposes and effects of discovery. 
occurs, the closer is the plaintiff win rate to 50 percent. Plaintiff win rates among cases adjudicated in the last round (at trial) are 49.1 percent for labor cases, 48.5 percent for tort, 59.6 percent for contract, 60.9 percent for intellectual property, 22.6 percent for civil rights, and 21.7 percent for prisoner cases. Convergence toward 50 percent is by no means complete (particularly for civil rights and prisoner cases), but the tendency is clear. Despite the tendency toward roughly 50 percent plaintiff win rates, persistent deviations of $P$ from 50 percent may be consistent with either DE or AI theories. The low fourth round plaintiff win rates for prisoner and civil rights cases may reflect uninformed plaintiffs in those categories. On the other hand, one can rationalize deviations of $P$ from 50 percent within $\mathrm{DE}$ with asymmetric stakes or persistently high party uncertainty in estimating case quality (see Waldfogel, 1995).

\section{Conclusion}

The group of cases actually going to trial is a highly selected sample of filed cases. Because of settlement and adjudication occurring before trial, the distribution of expected plaintiff win rates among cases proceeding to trial is much narrower than the distribution among filed cases. Put another way, information is less asymmetric among the parties proceeding to trial than among the parties to all filed cases. In the basic AI model tried cases are drawn only from the tail of the filed case quality distribution with quality favorable to the informed party. Under AI the distribution of tried cases is a singly-truncated version of the distribution of filed cases. The process of actual pretrial adjudication and settlement, by contrast, appears to eliminate both high and low-quality cases from the pool proceeding to trial. Consequently, the selection of cases for trial results in plaintiff win rates at trial approaching 50 percent. The pattern of settlement in each pretrial round appears to reflect the presence of $\mathrm{AI}$, but the selection of cases for trial is not one-sided as the AI model predicts. Instead, cases both above and below the decision standard are settled or adjudicated out of the filed pool, leading to a tendency toward central, not extreme, plaintiff win rates at trial. 


\section{References}

Bebchuk, Lucian A. "Litigation and Settlement under Imperfect Information." RAND Journal of Economics 15, no. 3 (1984): 404-415.

Cooter, Robert D. and Daniel L. Rubinfeld. "An Economic Model of Legal Discovery." Journal of Legal Studies 23 (January 1994):435-463.

Eisenberg, Theodore. "Testing the Selection Effect: A New Theoretical Framework with Empirical Tests." Journal of Legal Studies 19 (June 1990):337-358.

Eisenberg, Theodore. "The Relationship between Plaintiff Success Rates before Trial and at Trial." Journal of the Royal Statistical Society series A, 154, no. 1 (1991):111-116.

Froeb, Luke. "Adverse Selection of Cases for Trial" International Review of Law and Economics 13, (1993): 317-324.

Gould, John P. "The Economics of Legal Conflicts." Journal of Legal Studies 2, (1973):279-300.

Grossman, Gene M. and Michael L. Katz. "Plea Bargaining and Social Welfare." American Economic Review 73 (1983): 749-757.

Hay, Bruce L. "Civil Discovery: Its Effect and Optimal Scope." Journal of Legal Studies 23 (January 1994): 481-515.

Hylton, Keith N. "Asymmetric Information and the Selection of Disputes for Litigation." Journal of Legal Studies 22 (January 1993):187-210.

Kessler, Daniel, Thomas Meites, and Geoffrey P. Miller "Explaining Deviations from the Fifty Percent Rule" A Multimodal Approach to the Selection of Cases for Litigation." Journal of Legal Studies 25, no. 1 (1996):233-59.

Landes, William M. "An Economic Analysis of the Courts." Journal of Law and Economics 14, (1971): 61-107.

Nalebuff, Barry. "Credible Pretrial Negotiation." RAND Journal of Economics 18, (Summer 1987): 198-210.

Priest, George and Benjamin Klein. "The Selection of Disputes for Litigation." Journal of Legal Studies 13 (January 1984): 1-56.

Shavell, Steven. "Any Frequency of Plaintiff Victory is Possible." Journal of Legal Studies 25 (June 1996): 493-501. 
Siegelman, Peter and John J. Donohue III. "The Selection of Employment Discrimination Disputes for Litigation: Using Business Cycle Effects to Test the Priest/Klein Hypothesis." Journal of Legal Studies 24 (1995): 427-62.

Siegelman, Peter and Joel Waldfogel. "Toward a Taxonomy of Disputes: New Evidence through the Prism of the Priest and Klein Model." Unpublished Manuscript. The Wharton School, 1997.

Spier, Kathryn E. "The Dynamics of Pretrial Negotiation." Review of Economic Studies 59 (1992):93-108.

Waldfogel, Joel. "The Selection Hypothesis and the Relationship between Trial and Plaintiff Victory." Journal of Political Economy 103, no.2 (1995):229-260.

Wittman, Donald. "Is the Selection of Cases for Trial Biased?" Journal of Legal Studies 14 (January 1985):185-214.

Wittman, Donald. "Dispute Resolution, Bargaining, and the Selection of Cases for Trial: A Study of the Generation of Biased and Unbiased Data." Journal of Legal Studies 17 (1988): 313-52. 


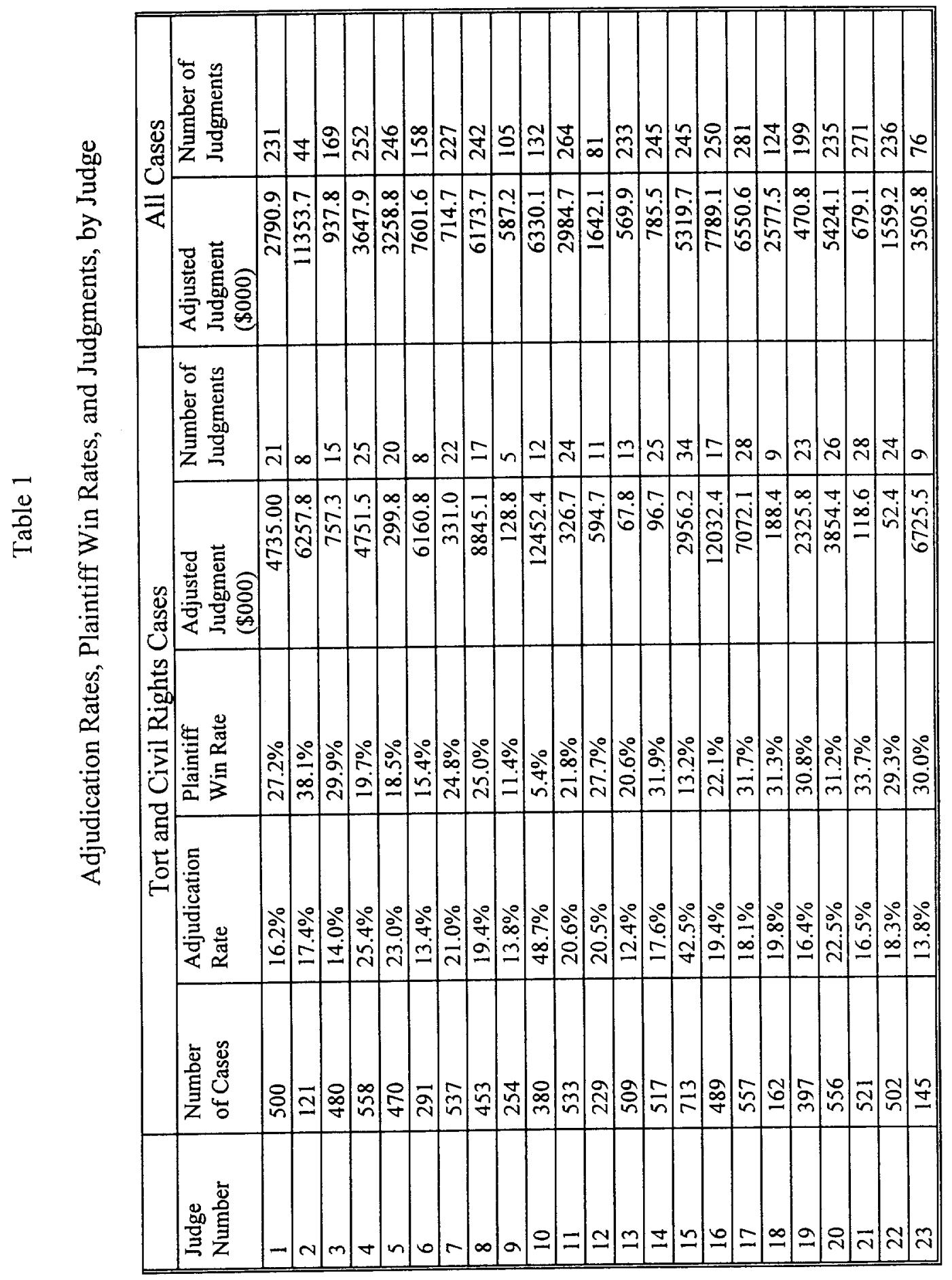




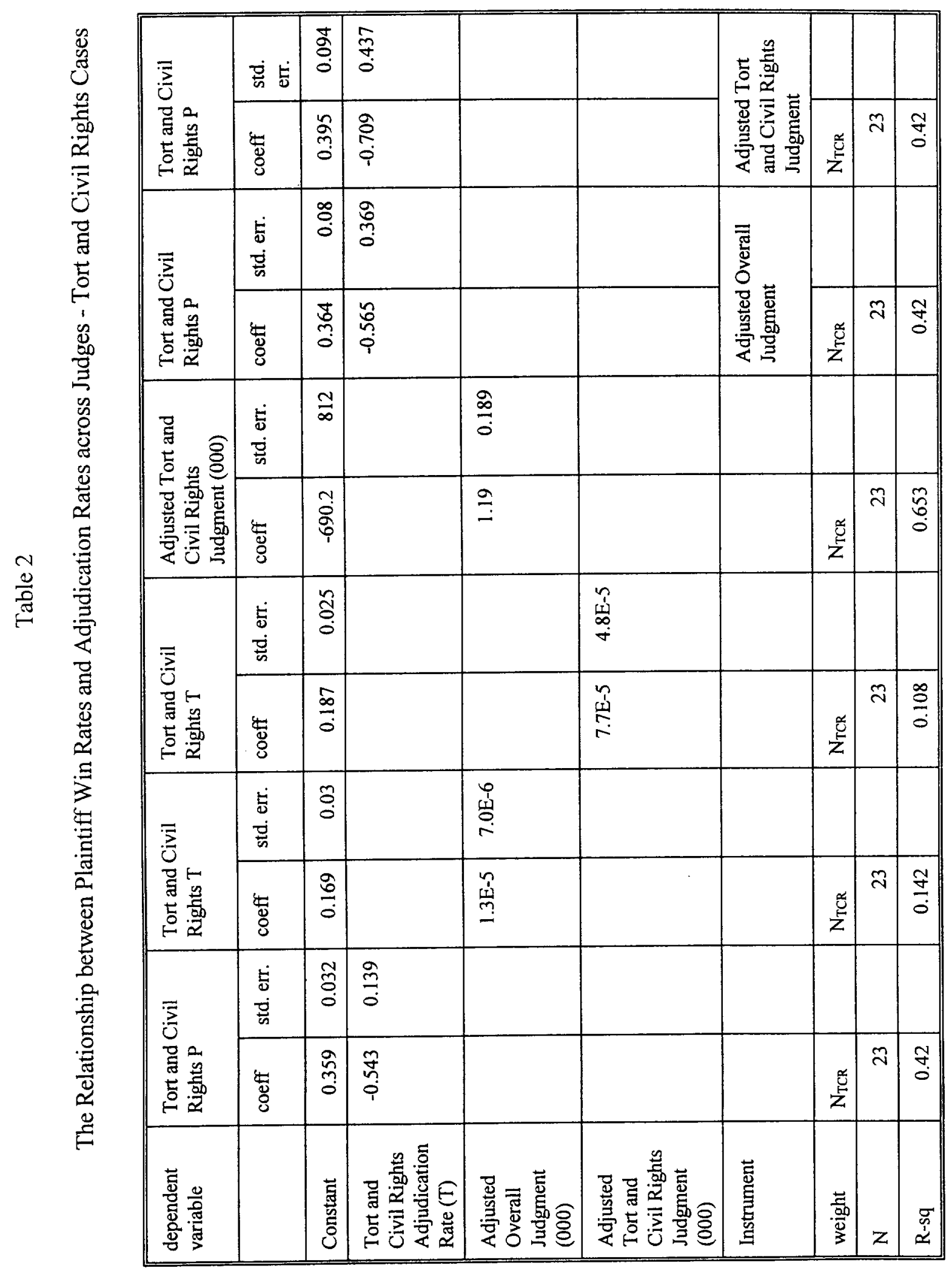


Table 3

Variables Related to Information Asymmetry

\begin{tabular}{|l|c|c|c|}
\hline & $\begin{array}{l}\text { Percent of Plaintiffs } \\
\text { who are pro se }\end{array}$ & $\begin{array}{l}\text { Percent of plaintiffs } \\
\text { that are institutions }\end{array}$ & $\begin{array}{l}\text { Percent of defendants } \\
\text { that are institutions }\end{array}$ \\
\hline Contracts & 0.0 & 80.2 & 71.4 \\
\hline Tort & 5.9 & 3.7 & 72.6 \\
\hline Civil Rights & 21.1 & 6.9 & 76.1 \\
\hline Prisoner & 64.4 & 0.0 & 100.0 \\
\hline Labor & 5.0 & 72.4 & 86.7 \\
\hline $\begin{array}{l}\text { Intellectual } \\
\text { Property }\end{array}$ & 0.0 & 77.5 & 85.2 \\
\hline
\end{tabular}

Note: From Siegelman and Waldfogel (1997), tables 4 and 5. 


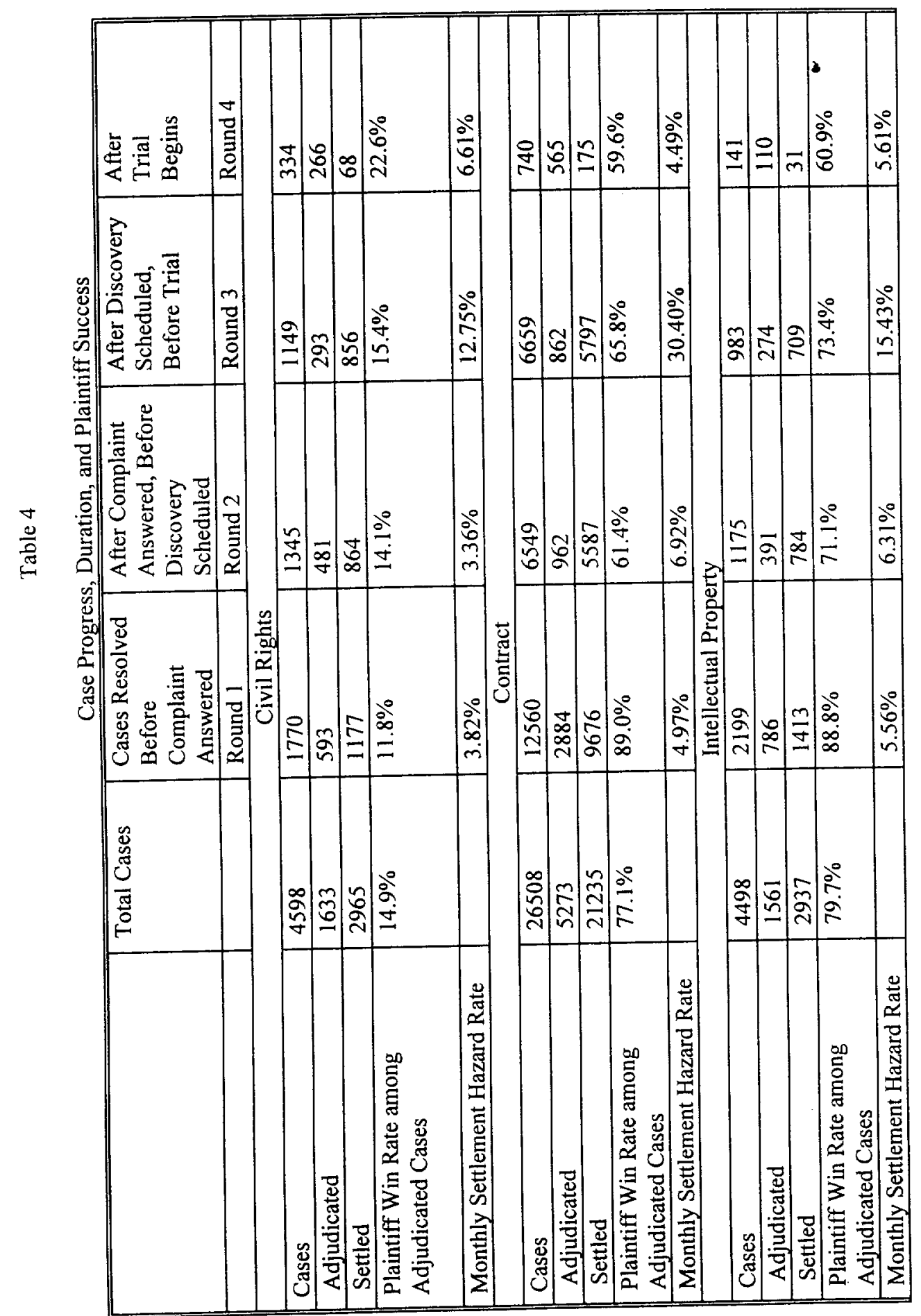




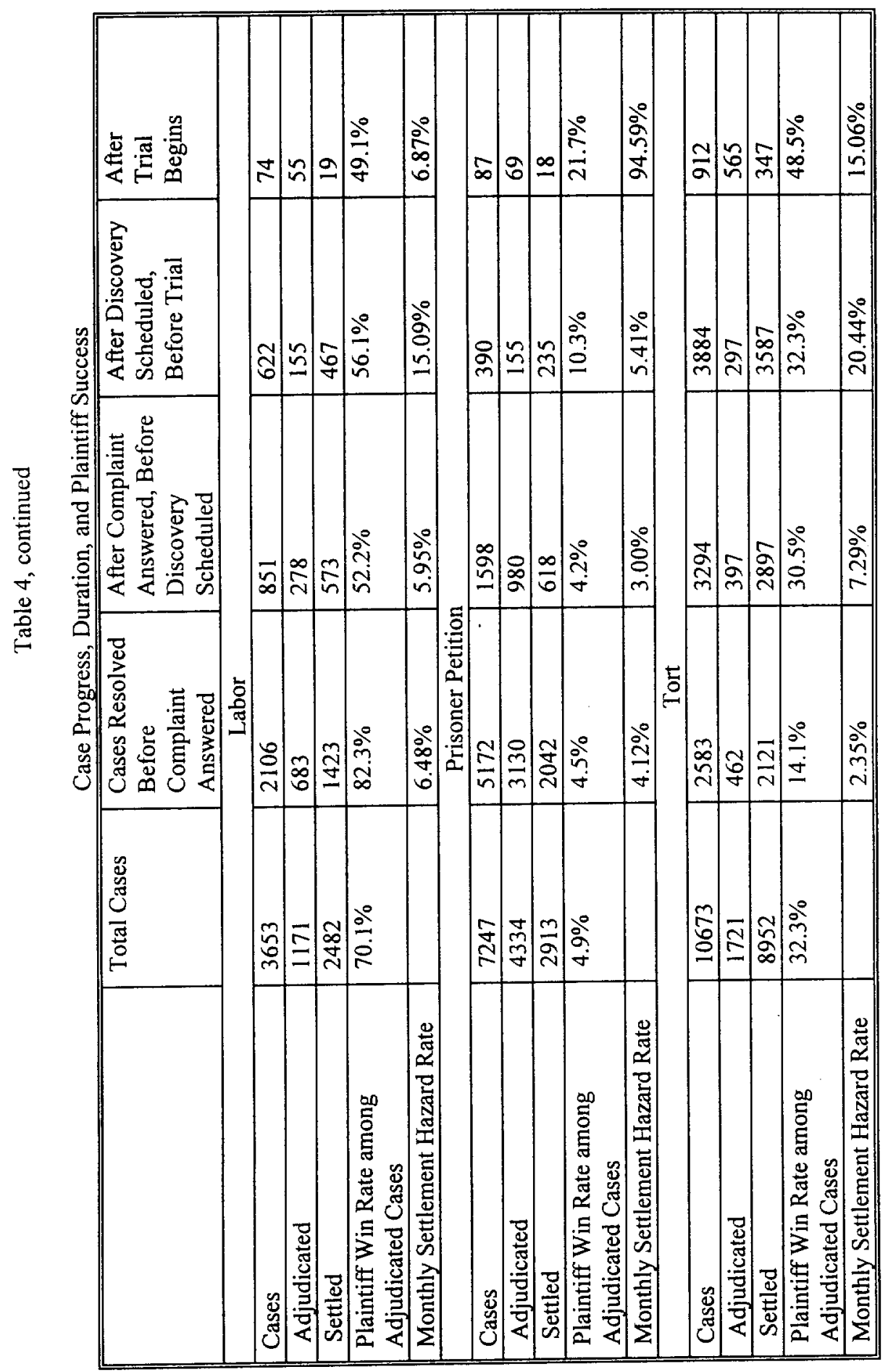


Figure 1

\section{Judgments and Adjudication Rates by Judge, SDNY}

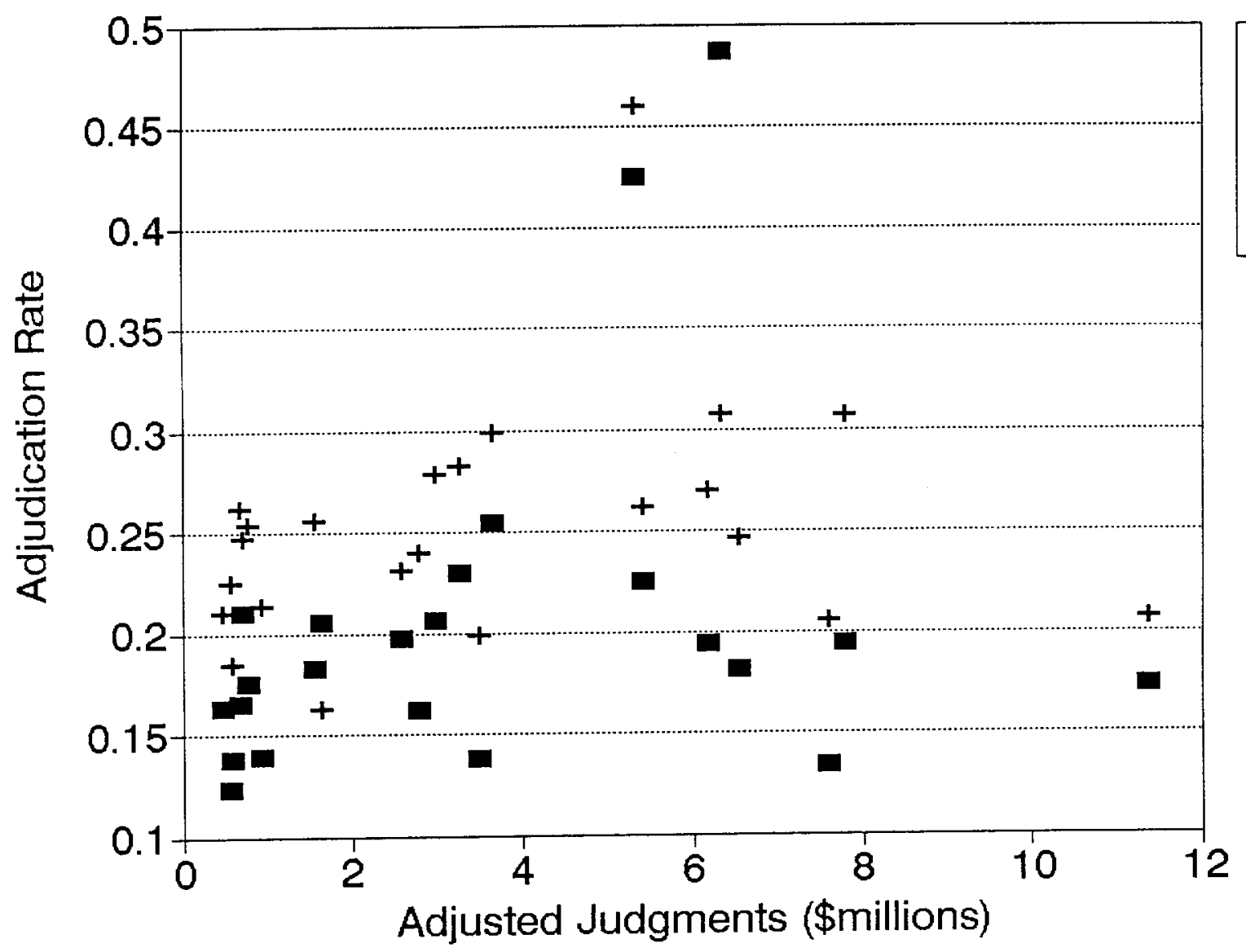

Tort, Civ. Rts. $+$ All Cases 
Figure 2

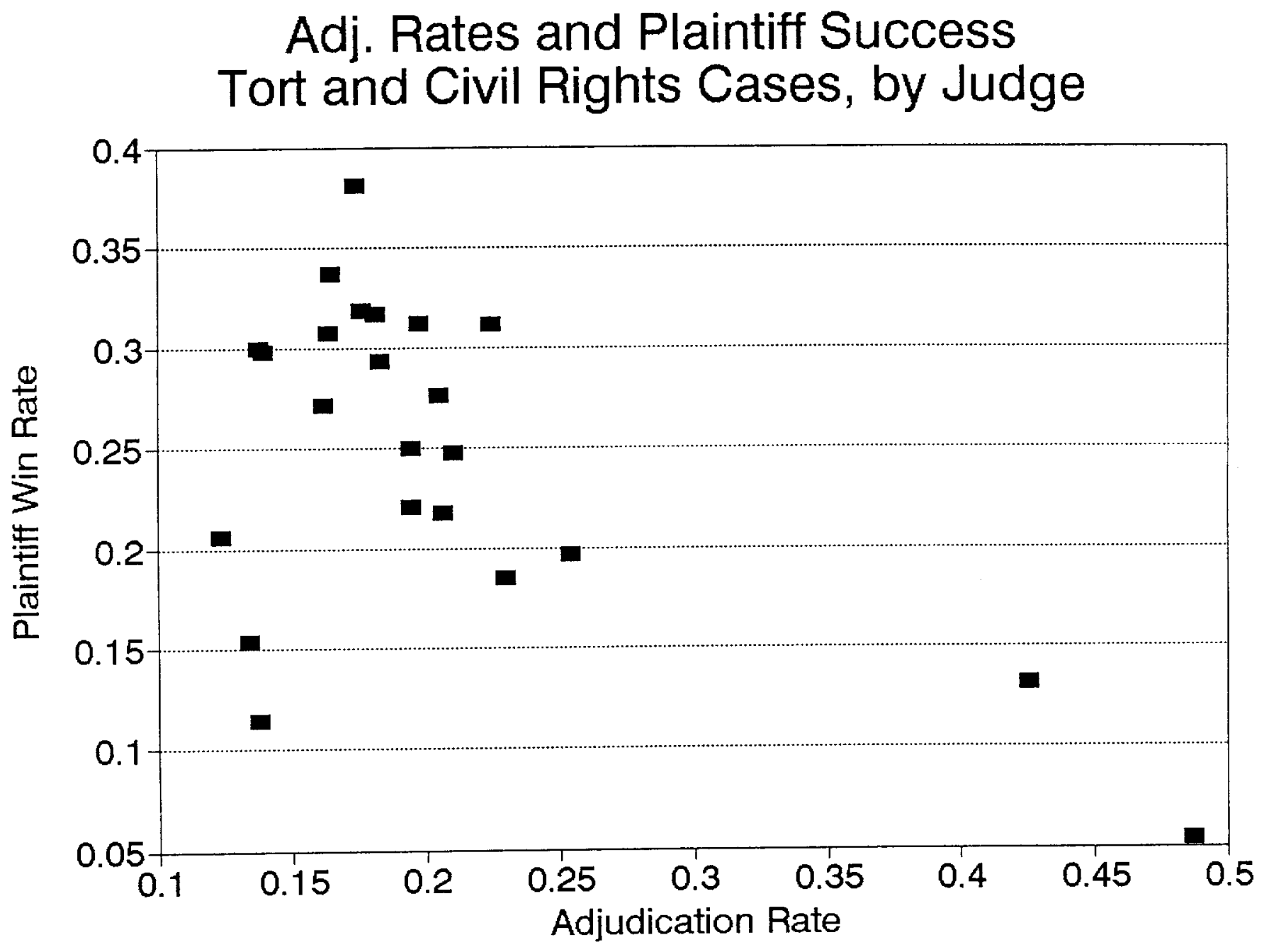


Figure 3

Cases Culled by Early Adjudication

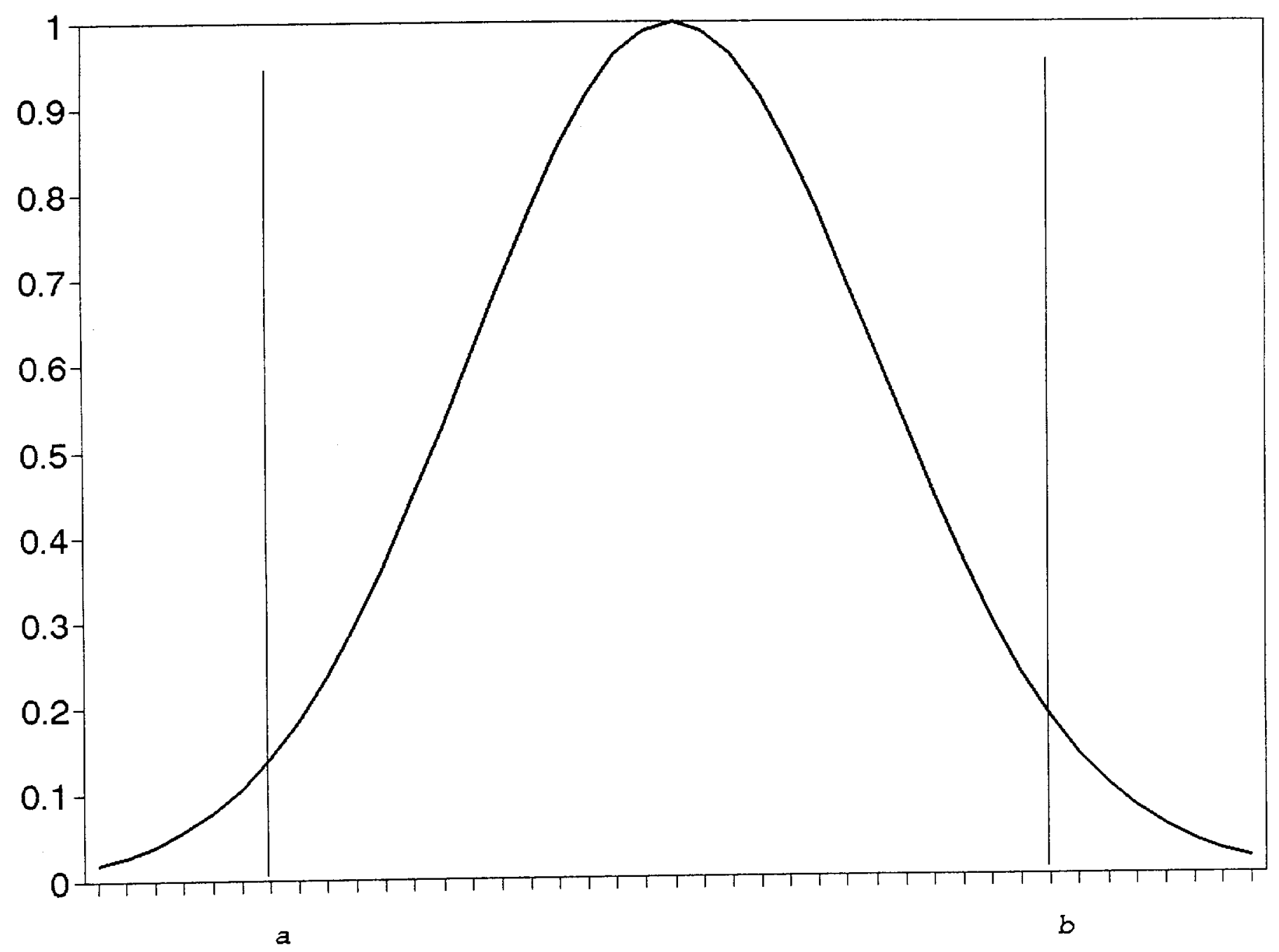


Figure 4

\section{Plaintiff Win Rate in Adjudicated Cases by Timing of Adjudication}

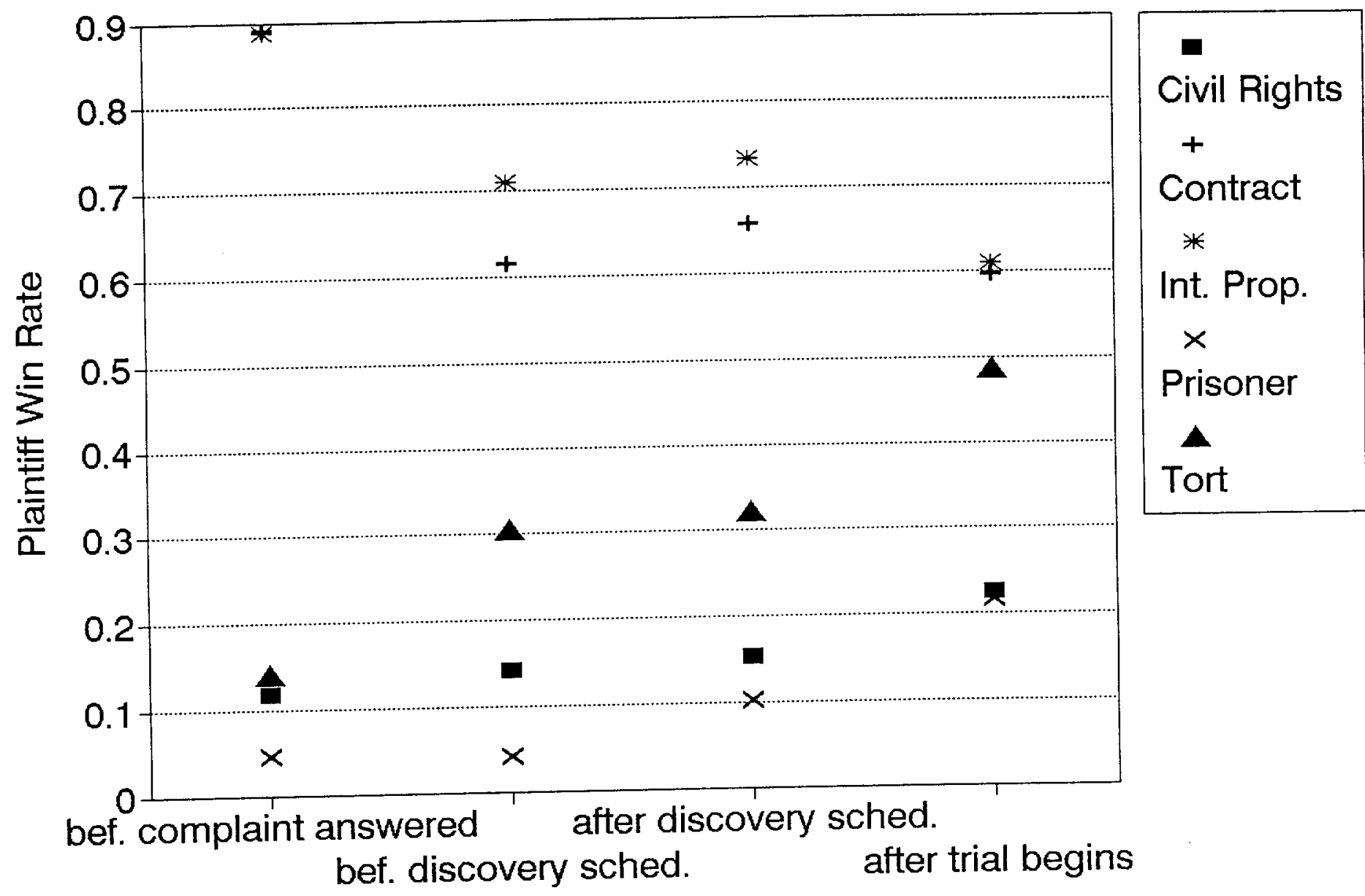

